\title{
CONF-950840--3
}

\section{ANALYSIS OF THE SURFACE STRUCTURE OF HFCVD DIAMOND FILMS}

Prabhjot Mehta $^{1}$, R.E. Clausing ${ }^{2}$, L. Heatherly ${ }^{2}$, T. Thundat ${ }^{2}$, and C.S. Feigerle ${ }^{1}$

${ }^{1}$ Dept. of Chemistry, University of Tennessee, Knoxville, TN 37996-1600

2Oak Ridge National Laboratory, PO Box 2008, Oak Ridge, TN 37831-6093

Key words : AFM, diamond, HFCVD, morphology, SEM.

\begin{abstract}
Structure analysis was carried out on various surface features of diamond films using scanning electron microscopy (SEM) and atomic force microscopy (AFM). The films were grown via hot filament assisted chemical vapor deposition (HFCVD) in methane and hydrogen gas mixtures. We investigated the surfaces of films grown under parameters selected to produce certain textures or surface features such as penetration twins or hopper shaped faces. The SEM images of these films show that the $\{100\}$ planes are usually flatter than the $\{111\}$. The $\{111\}$ planes show interesting growth features. The "hopper" shaped structures were imaged in the tapping mode of the $\mathrm{AFM}$, and the angles between planes and their orientations have been determined. These AFM and SEM images are presented with quantitative analyses of the exposed surfaces. Detailed quantitative information will be useful in understanding the growth of these films.
\end{abstract}

\section{Introduction}

Diamond has been of great interest due to its extreme properties, which can be exploited for various applications [1]. Chemical vapor deposition of diamond has tremendously increased the applications of diamond films in various fields. The growth mechanisms and the processes of nucleation are quite complex, and ideas about them continue to be developed [2-4]. All mechanisms proposed so far recognize the imporant link between growth processes and surface morphology, however, relatively limle has been done to relate observed morphology and growth features to growth mechanisms.

SEM images reveal the surface, however they do not provide quantitative information such as the identification of planes, etc. Transmission electron microscopy (TEM) is a relatively difficult technique, especially when used on diamond; the hardest material. Recent advances in scanning probe microscopy holds promise, however, that field also has its set of difficulties. Scanning tunneling microscopy (STM) is difficult on diamond due to its insulating properties. Doping the films with boron has made acquiring STM images easier [5]. However, for diamond which is free from impurities. AFM seems to be better suited even though atomic resolution is almost impossible to achieve. Numerous papers have been published on STM and AFM of the surface of diamond films, but they do not include much quantitative analysis. 


\section{DISCLAIMER}

Portions of this document may be illegible in electronic image products. Images are produced from the best available original document. 


\title{
ANALYSIS OF THE SURFACE STRUCTURE OF HFCVD DIAMOND FILMS
}

Prabhjot Mehta $^{1}$, R.E. Clausing ${ }^{2}$, C.S. Feigerle ${ }^{1}$, L. Heatherly ${ }^{2}$, and T. G.Thundat ${ }^{2}$

${ }_{1}$ Dept. of Chemistry, University of Tennessee, Knoxville, TN 37996-1600

2Oak Ridge National Laboratory, PO Box 2008, Oak Ridge, TN 37831-6093

Surface structure analysis was carried out on various surface features of diamond films using scanning electron microscopy (SEM) and atomic force microscopy (AFM). The films were grown via hot filament assisted chemical vapor deposition (HFCVD) in methane and hydrogen gas mixtures. We investigated the surfaces of films grown under selected parameters to produce certain textures or surface features such as penetration twins or hopper shaped faces. The SEM images of these films show that the (100) planes are usually flatter than the (111). The (111) planes show interesting growth features. We investigated the "hopper" shaped structures in particular. These were imaged in the tapping mode of the AFM, and the angles between planes and their orientation has been determined.

Films grown with different parameters show a morphology with large, smooth (100) planes parallel to the substrate as imaged in the SEM. These facets seem to be rough on a nanometer scale as observed in the AFM. Some areas show nanometer scale steps, ridges etc. These AFM and SEM images are presented with quantitative analyses of the exposed surfaces. Detailed quantitative information will be useful in understanding the growth of these films.

\section{DISCLAIMER}

\begin{abstract}
This report was prepared as an account of work sponsored by an agency of the United States Government. Neither the United States Government nor any agency thereof, nor any of their employees, makes any warranty, express or implied, or assumes any legal liability or responsibility for the accuracy, completeness, or usefulness of any information, apparatus, product, or process disclosed, or represents that its use would not infringe privately owned rights. Reference herein to any specific commercial product, process, or service by trade name, trademark, manufacturer, or otherwise does not necessarily constitute or imply its endorsement, recommendation, or favoring by the United States Government or any agency thereof. The views and opinions of authors expressed herein do not necessarily state or reflect those of the United States Government or any agency thereof.
\end{abstract}


Everson et al [6] have reported on indexing the faces and orientations of the sloping triangular defects appearing on the $\{100\}$ surface.

In this paper we report on some of the surface features of diamond films as seen in SEM and further investigated using AFM in the tapping mode. Quantitative analysis was done on the AFM images and their results and implications are presented here.

\section{Experiment}

The films were grown in a hot filament assisted chemical vapor deposition (HFCVD) chamber at a pressure of $\sim 40$ Torr. A carburized tungsten wire filament was used in the quartz growth chamber. The feed gas mixture was composed of $1 \%$ methane in hydrogen, and the flow rate was $50 \mathrm{sccm}$. Films were grown on $\mathrm{Si}(001)$ wafers, which were treated first by scratching with diamond paste and next by rinsing with acetone and methanol in an ultrasonic bath. The filament and substrate temperatures used were $2120^{\circ} \mathrm{C}$ and $1050^{\circ} \mathrm{C}$ respectively, which were measured using an optical pyrometer without any corrections for the emissivity or reflections. The substrate was positioned $\sim 10 \mathrm{~mm}$ from the filament. The films were grown for 16 hours.

The films were imaged using a Hitachi S-800 SEM, and the geometry of the various features were analyzed quantitatively using a Digital Instruments Nanoprobe III AFM to identify the orientations of the surface facets. The tapping mode of the AFM was used to obtain images of the surfaces of these films, which were then analyzed using the Nanoscope III software program. All angles were measured from unprocessed images. The AFM was operated in air at room temperature. For the AFM data, commercially available microfabricated silicon cantilevers were used with a spring constant of $-35 \mathrm{~N} / \mathrm{m}$.

\section{Results}

Figure 1 shows the representative SEM image of a film containing crystallites with hopper shaped structures. Planes with 3-fold and 4-fold symmetry are easily identified as the $\{111\}$ and $\{100\}$ planes, and these planes are oriented such that the polycrystalline film appears to be $<110>$ oriented. The growth rate was $\sim 1.28 \mu / \mathrm{hr}$, and the ratio of the growth rate in the $\langle 100\rangle$ to that in the $<111\rangle$ was $-0.87(\alpha=1.5)$. The $(100)$ planes appear flatter than the $\{111\}$ planes. However, in the samples of interest, indented hopper shaped features are present where the $\{111\}$ planes would normally be. These features indicalte that planes with higher indices than the usual $\{100\}$ and $(111\}$ are forming.

AFM images of these and similar samples have been recorded and their surface structure analyzed. The angles between planes were measured, and based on these angles, the planes have been indexed. The identification of these planes, we believe, will be useful in understanding the mechanisms acting during the growth of these films. The angles between a $\{\mid(x)\}$ plane and one of the adjacent planes inside the hopper (these planes sharing a common [1] 0 ) direction) had an average value of $68.6^{\circ}$; and that between $\{(x))$ and another one of the planes inside the hopper (these also sharing a common [11()] direction) was found to be $75.6^{\circ}$. These indicate that the adjacent planes are likely of the fumilies of $\{221\}$ and (331) respectively. Table I shows a full set of measurements and calculated values. The table is arranged into 3 groups of angles, those between one of the $\{1(\mathrm{X})$ and its adjacent hopper plane, those 


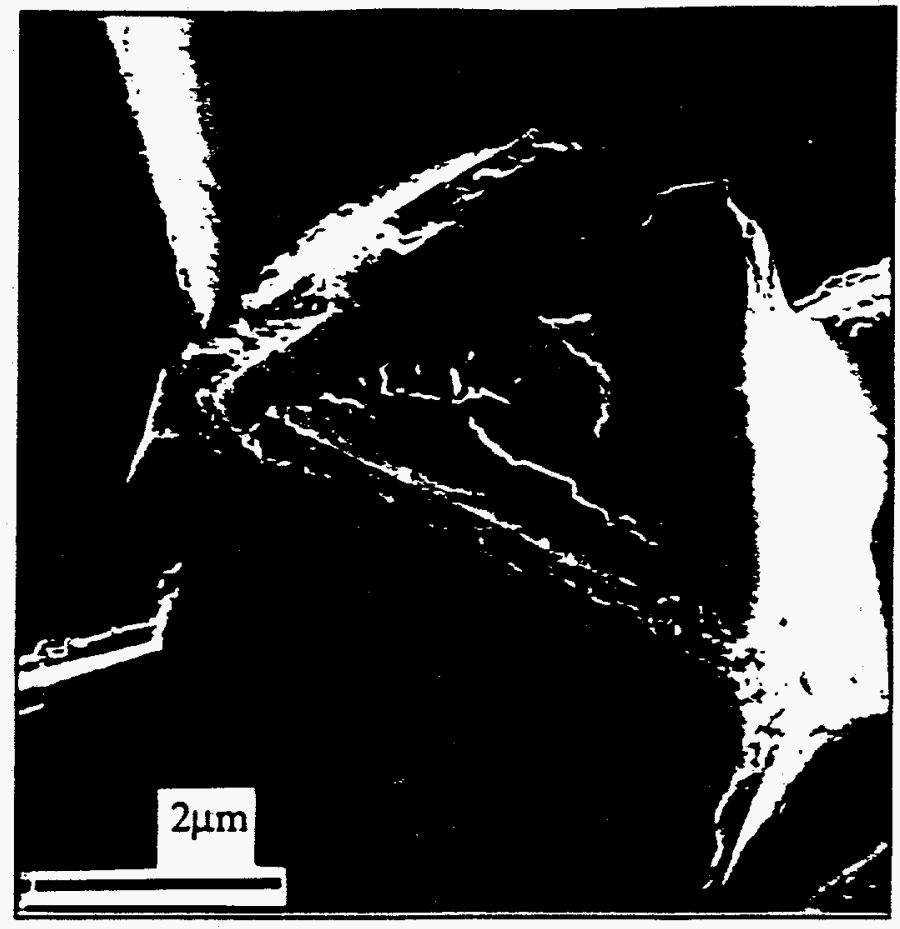

Fig. 1. An electron micrograph of a (111) face. The $<110\rangle$ edges are seen to be broken. (100) faces appear to be flat. The growth rate on these films was $-1.28 \mu / \mathrm{hr}$.

\begin{tabular}{|c|c|c|c|c|}
\hline Planes & $\begin{array}{l}\text { Calculated } \\
\text { angle between } \\
\text { the planes } \\
\text { (deg.) }\end{array}$ & $\begin{array}{l}\text { Average } \\
\text { of measured } \\
\text { angles } \\
\text { (deg.) }\end{array}$ & $\begin{array}{l}\text { Difference } \\
\text { between avg. } \\
\text { and calculated } \\
\text { (deg.) }\end{array}$ & $\begin{array}{l}\text { Standard } \\
\text { Deviation } \\
\text { (deg.) }\end{array}$ \\
\hline 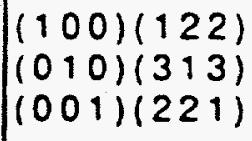 & $\begin{array}{l}70.53 \\
76.74 \\
70.53\end{array}$ & $\begin{array}{l}68.6 \\
75.6 \\
67.5\end{array}$ & $\begin{array}{l}1.9 \\
1.1 \\
3.0\end{array}$ & $\begin{array}{l}1.46 \\
3.89 \\
1.76\end{array}$ \\
\hline 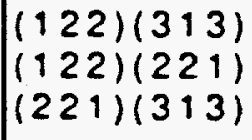 & $\begin{array}{l}32.73 \\
27.26 \\
32.73\end{array}$ & $\begin{array}{l}29.4 \\
23.9 \\
25.5\end{array}$ & $\begin{array}{l}3.3 \\
3.4 \\
7.2\end{array}$ & $\begin{array}{l}4.04 \\
0.95 \\
2.06\end{array}$ \\
\hline 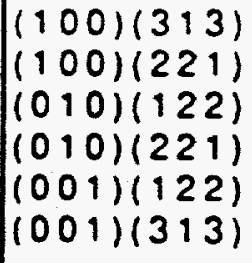 & $\begin{array}{l}46.51 \\
48.19 \\
48.19 \\
48.19 \\
48.19 \\
46.50\end{array}$ & $\begin{array}{l}42.8 \\
48.0 \\
53.1 \\
52.0 \\
51.3 \\
46.6\end{array}$ & $\begin{array}{l}3.7 \\
0.2 \\
.4 .8 \\
.3 .8 \\
.3 .1 \\
.0 .1\end{array}$ & $\begin{array}{l}2.02 \\
2.88 \\
3.31 \\
2.22 \\
2.28 \\
1.88\end{array}$ \\
\hline
\end{tabular}

Table l. The analysis of the data tuken for the identification of the planes. 


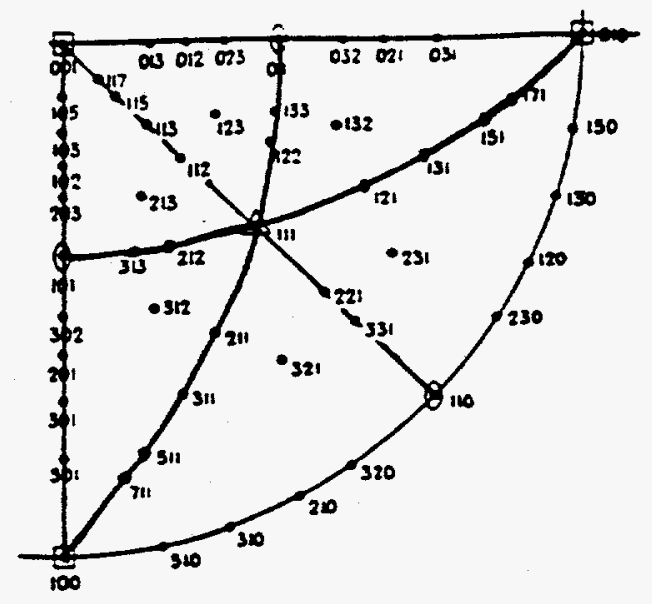

Fig. 2. The standard (001) projection of a cubic crystal. Table I. Shows the analysis of the data taken for the identification of the planes.

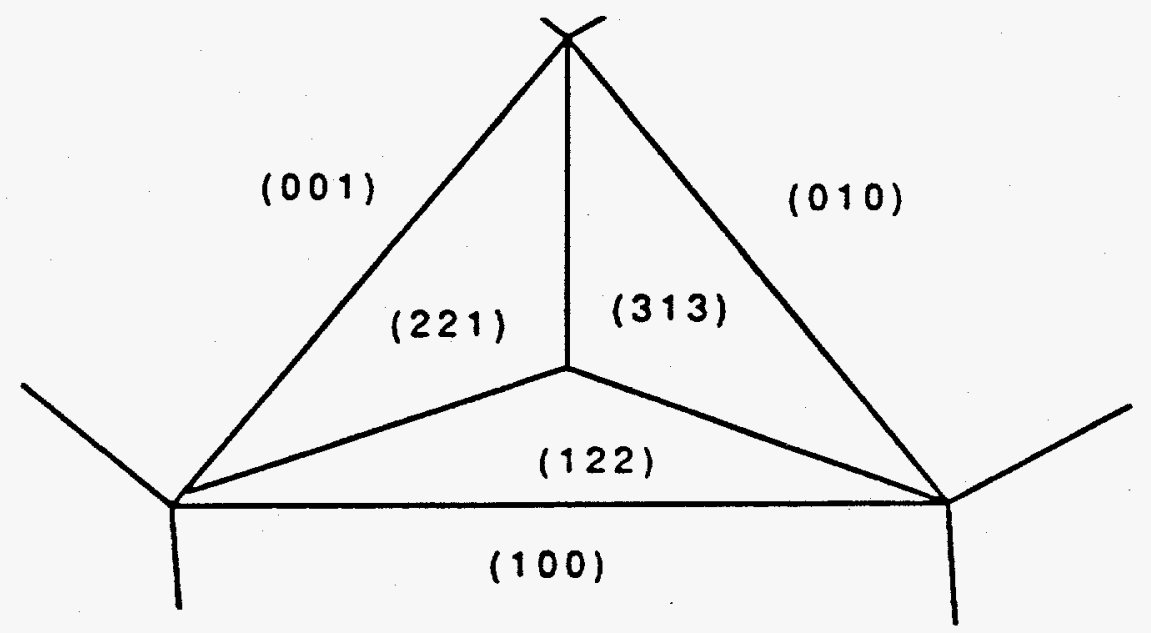

Fig. 3. A schematic of a hopper shaped face. The faces have been indexed as suggested by our calculations and observations of the angles that these faces make with each other are presented in Table 1. 
between two adjacent hopper planes, and those between one of the $[100\}$ and the other two non-adjacent hopper planes. The angles being reported have been averaged for different sets of same planes seen on the same or on a different image. For each set, the measurements were repeated about ten times. Table I shows the average and the standard deviations of the angles measured as well as the calculated values. The angles between some of the $\{100\}$ planes were also measured, to check the validity of the measured angles. The average value measured was $90.7^{\circ}$. Sources of error in these measurements could be from the piezo calibration and thermal drift. An error of -0.5 percent in the $z$-piezo calibration approximates to $\sim 3^{\circ}$ in the angle measurements.

\section{Discussion}

The planes were indexed by comparison of the measured angles with those obtained from the standard (001) projection with the poles of the hopper facets identified as shown in fig. 2. The angle between the $(100)$ and one of the adjacent planes inside the hopper was measured to have an average value of $68.6^{\circ}$ with standard deviation $1.46^{\circ}$. The closest match seems to be the $70.53^{\circ}$ for the (122) plane. The $75.6^{\circ}$ with standard deviation $3.89^{\circ}$ corresponds best with the $76.74^{\circ}$ for the angle between (313) and the (010) plane. The additional angles measured between these higher index planes confirm this identification.

The presence of near (221) and (331) faces inside the hopper suggests a growth mechanism involving steps [7] nucleated at an outside edge and proceeding inward into the hopper. Such stepwise grow'th would lead to planes of the type $(221),\{331)$ etc. depending on the relationships between nucleation of steps and their propagation over the underlying (111) plane. Figure 3 is a diagram showing the relationship of the planes in the hopper to the surrounding $\{I(K)\}$ planes and corresponds to those shown in fig. 1 and the angles listed in Table $\vec{j}$.

We believe quantitative crystallographic information such as that presented here can be used to suggest and test models of growth mechanisms, especially when combined with parametric grou'th studies.

\section{Acknowledements}

This research was supported by NSF grant \#CTS-9202575 and by the Division of Material Sciences, U.S. Department of Energy under contract \#DE-AC05-84OR21400 with Martin Marietta Energy Systems, Inc.

\section{References}

1. J. C. Angus and C. C. Hayman. Science 241. 913 (1988).

2. M. Frenklach and K. E. Spear. J. Mater. Res. 3, 133 (1988).

3. S. J. Harris, Appl. Phys. Lett. 56, 2298 (1990).

4. M. Tsuda. M. Nakajima, and S. Oikawa. J. Am. Chem. Soc. 108, 5780 (1986).

5. T. J. Kreutz, R. E. Clausing, L. Ileatherly,jr., R. J. Warmack, T. Thundat, C. S. Feigerle, and $K$. Windeli: J. l'his. B. (In press).

6. M. P. Everson, M. A. T:mur. and D. Scholl, B. R. Stoner, S. R. Sahaida, and J.

P. Bade. J. Appl. Phys. 7511 . 1(1) 11994).

7. W.K. Burton, N. Cahrer.t. I. C Iromk. Philosoph. Trans. R. Soc. London A

243, 299 (1951).

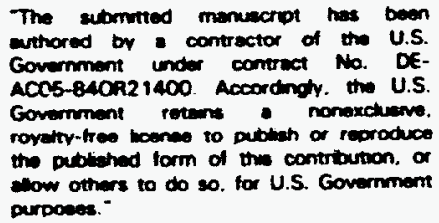

